\title{
NOVEL APPROACHES TO CONTROLLING FRUIT PATHOGENS
}

\author{
R.E. BEEVER ${ }^{1}$, K.M. PLUMMER ${ }^{2}$ and K.V. WURMS ${ }^{3}$ \\ ${ }^{1}$ Landcare Research, Private Bag 92170, Auckland, New Zealand \\ ${ }^{2}$ University of Auckland, clo HortResearch, Mt Albert Research Centre, \\ Private Bag 92169, Auckland, New Zealand \\ ${ }^{3}$ HortResearch, Ruakura Research Centre, Private Bag 3123, Hamilton, \\ New Zealand
}

Corresponding author: beeverr@landcareresearch.co.nz

\begin{abstract}
Despite many years of research, fruit loss due to disease is still a major factor in fruit production worldwide. Recent advances in understanding the biology of fruit pathogens, and the complex interactions between host plants and pathogens, offer opportunities for novel ways to better manage these diseases. These opportunities are reviewed with particular reference to the major fruit pathogens (Botrytis, Colletotrichum, Cryptosporiopsis, Monilinia and Venturia) and fruit crops (kiwifruit, apple, grape, avocado and stonefruit) in New Zealand. Approaches based on fungal biology include the possible use of fungal viruses as biocontrol agents, the use of reduced-pathogenicity strains of pathogens as biocontrol agents, and using fungal genomic data and molecular techniques to identify key pathogenicity factors as targets for novel control products. Approaches based on host defence mechanisms include enhancing expression of host defence responses such as antifungal proteins and volatiles through marker-assisted breeding and post-harvest treatments.
\end{abstract}

Keywords: fruit pathogens, mycoviruses, reduced-pathogenicity strains, pathogenicity factors, host defence.

\section{INTRODUCTION}

Fungal pathogens are a major problem in fruit production in New Zealand, especially post-harvest because of the distance to many overseas markets. The major pathogens and fruit crops include Botrytis cinerea causing grey mould of kiwifruit and grape, species of Colletotrichum, especially C. gloeosporioides (sexual stage = Glomerella cingulata), causing bitter rot of apple and ripe rot of avocado, Cryptosporiopsis actinidiae causing ripe rot of kiwifruit, Monilinia fructicola causing brown rot of stonefruit, and Venturia inaequalis causing black spot (scab) of apple.

Most of these fungi were all major pathogens in 1925 as outlined in the pioneer publication of Cunningham (1925). At that time, chemical control was recognised as a major tool for managing fruit diseases but the spectrum of mainly broad action protectant fungicides available was limited and remained so until the 1960s (Atkinson 1971). The modern era of highly active, often relatively specific fungicides began in the late 1960s with the release of the benzimidazole fungicide benomyl (Byrde \& Jordan 1977) and has continued apace since then. However, the appearance of fungicide-resistant strains (Hartill 1986; Beever et al. 1989) reduced the efficacy of such products and, coupled with increasing consumer concerns over chemical residues, there is an imperative to develop new approaches. This is particularly the case for post-harvest storage pathogens, such as those of kiwifruit, for which pre-harvest chemical treatments may be ineffective either because the pathogen is in a latent state $(C$. actinidiae $)$ or the chemicals cannot target the infection site created during harvest $(B$. cinerea), yet post-harvest treatments are highly restricted because of unacceptable residues. 
There are many 'novel' approaches to disease control in general and fruit rot control in particular. This paper outlines some of the research being undertaken in New Zealand on these approaches, although excluded from this review is the use of 'classic' biocontrol agents, which is covered in a companion paper (Elmer et al. 2005). Two broad approaches are recognised, the first targeting the pathogens, the second the host.

\section{APPROACHES BASED ON FUNGAL BIOLOGY \\ Fungal viruses for biocontrol}

Fungi, including fruit pathogens, are attacked by a range of other organisms including other fungi and bacteria. Some of these agents have been exploited for biocontrol of fruit pathogens, such as $B$. cinerea, although direct attack is usually considered only one mechanism of action of successful agents (Elad \& Stewart 2004). Fungi are also attacked by viruses. While many fungal viruses (mycoviruses) apparently have little effect on the fitness of their host fungus, one group - the hypoviruses - has attracted particular attention because of their dramatic debilitating effect on the host (Dawe \& Nuss 2001).

A study of the mycoviruses of $B$. cinerea and $M$. fructicola found that, while over $70 \%$ of strains harbour viruses, they have little if any effect on their hosts (Howitt et al. 1995; Tsai et al. 2004). During this work, a new class of fungal viruses (ssRNA viruses) in $B$. cinerea was discovered (Howitt et al. 2001); these viruses have the potential for being modified to be more pathogenic, but a lot more basic understanding is required before this could be realised. Recently a virus has been discovered in Europe that reduces pathogenicity of $B$. cinerea (Castro et al. 2003) and perhaps this could be developed in the future for biocontrol.

\section{Reduced-pathogenicity strains for biocontrol}

Classically the use of fungi for biocontrol involves the use of other fungal species to control the target pathogen. A novel, and more subtle, approach involves the use of strains of the pathogens themselves as biocontrol agents. As such, this approach draws on precedents such as the use of mild virus strains to control viruses (e.g. mild strains of tobacco mosaic virus (TMV) were used in tomato production in New Zealand but have been superseded by genetically resistant cultivars) and the use of 'Dygal', a nontumour inducing strain of Agrobacterium tumefaciens, to control the bacterial disease crown gall.

This approach for control is based on the proposal that, because strains of the target fungus with reduced-pathogenicity will closely match the target fungus ecologically and physiologically, they may efficiently displace the target fungus from infection sites and/or stimulate host defences in advance of infection. The approach has been developed, for example, to provide control of the vascular pathogen Fusarium oxysporum where nonpathogenic strains show particular promise (Fravel et al. 2003). While there are few precedents with fruit pathogens, the possibility of such an approach has been demonstrated by showing that pre-inoculation with a non-aggressive strain of $B$. cinerea reduced the ability of a subsequently inoculated aggressive strain to cause lesions (Weeds et al. 2000). Furthermore, over 100 years ago the use of an attenuated strain of $B$. cinerea was found to induce resistance in begonia (Chester 1933). Similarly, reduced-pathogenicity isolates of $C$. gloeosporioides induced by genetic modification (GM) techniques induce resistance to pathogenic strains in avocado (Yakoby et al. 2002). Presently this approach is being explored for control of $C$. actinidiae on gold kiwifruit using both naturally occurring variants of reduced pathogenicity and strains selected for reduced pathogenicity in the laboratory using traditional fungal breeding techniques (R.E. Beever, unpubl. data).

\section{Exploiting fungal genomic data}

Understanding of how organisms, including plant pathogenic fungi, function at the cellular level is being revolutionised through advances in molecular biology. Genome sequences of several plant pathogens are now available and there is considerable effort worldwide to understand the biological implications of this explosion of knowledge especially in relation to the mechanisms whereby these fungi infect their hosts 
(e.g. Ebbole et al. 2004, Randall et al. 2005). Nevertheless, this is a substantial challenge, not the least because of the vast amount of data available from the DNA sequence of each fungus.

To date, the full genome sequence is not available for any fruit-pathogenic fungus, although it is anticipated the $B$. cinerea genome sequence will become available by the end of 2005 through the Broad Institute (http://www.broad.mit.edu/; Cambridge, Mass., USA) and the French sequencing institute Génoscope (http://www.genoscope.cns.fr/). On the other hand significant numbers of sequences of active genes (EST libraries) are available for $V$. inaequalis and $B$. cinerea and can be used to assist in identifying specific sequences that are important in the fungal infection process.

When V. inaequalis grows on cellophane, it differentiates plate-like structures within the cellophane that resemble the fungal feeding structures or stroma produced during apple leaf infection (Bowen et al. 2005). This situation provides an opportunity to study this critical infection structure in the absence of the host plant and promises to provide insights into the genes and gene products needed for this process. Once identified, these vulnerable stages in pathogen development can be targeted for novel approaches to achieve durable disease resistance (Leach et al. 2001; Ponciano et al. 2003). Another novel approach arises from the finding that fungi produce communication chemicals or pheromones. In the apple pathogen Colletotrichum gloeosporioides, it has been shown that a pheromone from yeast, and a similar peptide molecule found in C. gloeosporioides itself, both inhibit the development of appressoria (Al-Samarrai et al. 2002). It has been found that the same peptide pheromone also inhibits formation of infection structures in V. inaequalis (Chynoweth \& Plummer 2004). This raises the possibility, for example, that synthetic peptides could be developed that specifically target this stage of the infection cycle. While the exploitation of genetic information for disease control is in its infancy, the rapidity of progress in molecular biology is such that practical applications are likely to emerge within the next decade.

\section{APPROACHES BASED ON ENHANCING HOST DEFENSES}

Host resistance is very complex. Defence mechanisms may be expressed continuously throughout the life of a host plant, regardless of the presence or absence of a pathogen (constitutive resistance), or the defence machinery can be turned on at a particular point in time, either by the advent of a pathogen or by a sensitising treatment (inducible resistance). Furthermore, expression of constitutive and induced defence mechanisms may differ between host genotypes (e.g. cultivars), within various tissues or organs of the same genotype, and even at different developmental stages (Heath 1995). Nevertheless, manipulating these natural resistance processes offers opportunities to develop durable disease management. The kiwifruit host defence system is being explored in relation to control of $C$. actinidiae (K.V. Wurms, unpubl. data). As this fungus is not a major pathogen of other horticultural crops, very little work has been undertaken on its biology (Hill et al. 2004). However, C. actinidae is one of the principal causal agents of ripe rots, the most important disease problem of gold kiwifruit, and there is no current effective method for control of this disease (Fullerton \& Tyson 2002). Recent studies suggest that infection occurs in fruitlets during flowering, with the fungus residing as a latent endophyte in lenticels until disease symptoms manifest following 12-20 weeks of storage after harvest (Hill et al. 2004). Breaking of latency in storage may be triggered by a decline of host defence mechanisms or stimulation of fungal growth by host factors. Biochemical and genetic markers for processes and genes potentially involved in determining resistance are being targeted based primarily on knowledge of the interactions between $B$. cinerea and kiwifruit, especially $\mathrm{cv}$. Hayward. These indicate that phenolic compounds and pathogenesis-related (PR) proteins, especially chitinases, are involved in kiwifruit resistance to fungi (Wurms et al. 1997, 1999, 2003; Wurms 2005).

Once identified, such markers can be used in two ways. The first is as tools to screen breeding populations. Resistant lines can then be selected and developed through conventional breeding programmes or, if acceptable, produced through GM. A working 
example in New Zealand is the HortResearch apple breeding programme, which uses molecular markers linked to several genes for resistance to $V$. inaequalis, powdery mildew and woolly apple aphid to select for seedlings containing one or more of these genes. The ultimate aim is to pyramid genes to increase resistance durability and provide protection against multiple pests and diseases (Bus et al. 2000, 2002). Such molecular markers allow breeders to predict with a reasonably high degree of certainty which seedlings contain multiple genes, thus speeding up the breeding process (Bus et al. 2002).

The second use of biochemical and genetic markers for resistance is to guide development of post-harvest treatments. Treatment could involve the direct use of a chemical found to be associated with resistance. For instance, if a particular host volatile is shown to be antifungal, it may be possible to artificially introduce that volatile to the storage atmosphere. This method has already been demonstrated to be effective against post-harvest infections of B. cinerea on kiwifruit (Kulakiotu et al. 2004), and on blackberries and grapes (Archbold et al. 2000). However, considerations for practicality of use need to include cost, safety of the volatile at the intended usage concentration and product efficacy at low storage temperature. Another post-harvest approach is to apply treatments or compounds known to elicit particular defence mechanisms. For example, if chitinase activity is shown to be an important marker of resistance, it might be possible to either induce chitinase activity using a post-harvest treatment such as curing (Wurms et al. 1997; Wurms 2005), or by application of a known elicitor of chitinase activity, such as chitosan post-harvest dip or fruit coating.

Despite the advantages of being environmentally benign and residue free, use of host resistance in kiwifruit has been relatively unexplored because cultivation until recently was largely restricted to cv. Hayward (Michailides \& Elmer 2000), and there was little or no evidence of constitutive resistance of this cultivar to key pathogens such as B. cinerea (Brook 1990). However, when broader definitions of resistance were considered, it was demonstrated that this cultivar exhibited varying degrees of organspecific, age-related and inducible resistance to B. cinerea (Wurms et al. 1999). Moreover, a project aimed at cataloguing pest and disease resistance in gold kiwifruit breeding experiments has shown wide variation in the levels of resistance to $B$. cinerea, Sclerotinia and scale insects, even when the progeny arise from a single cross (M.G. Hill, pers. comm.). If resistance to $C$. actinidae is also variable, there are definite prospects for enhancing host resistance to this pathogen.

To identify genes potentially involved in resistance in the gold kiwifruit- $C$. actinidae interaction, gene expression will be micro-arrayed, and biochemical activity of putative defence compounds (PR proteins, synthetic enzymes and products of secondary metabolism and volatiles) will be monitored during storage and correlated with the onset of rots. The relationship between the most promising indicators of resistance will be further examined using real time PCR to quantify timing of expression relative to the onset of resistance, and by testing the ability of selected elicitors to activate genes of interest.

Although traditional and novel uses of host resistance to enhance disease control offer the prospects of sustainable and environmentally benign disease management, there are several caveats to consider. The diversion of resources into maintenance of defences against invaders may reduce yield (Smedegaard-Petersen \& Tolstrup 1985), particularly when defences are expressed constitutively throughout the life of a plant. Judicious selection of host resistance factors is also important to prevent loss of useful organisms on the fructoplane. Successful development of host resistance requires an investment in long-term research, particularly if resistance factors are to be harnessed through conventional breeding rather than by GM. However, identification of key markers of resistance and compounds that elicit these genes will greatly accelerate this process.

\section{ACKNOWLEDGEMENTS}

Research outlined here has been primarily funded by the New Zealand Foundation for Research, Science and Technology, with support of the fruit industry (Zespri Ltd 
and Pipfruit New Zealand Ltd), Auckland University, the National Centre for Advanced Bio-Protection Technologies and the Marsden Fund.

\section{REFERENCES}

Al-Samarrai TH, Sullivan PA, Templeton MD, Farely PC 2002. Peptide inhibitors of appressorium development in Glomerella cingulata. FEMS Microbiology Letters 209: 203-207.

Archbold DD, Hamilton-Kemp TR, Fallik E 2000. Aroma volatiles as modulators of postharvest mold development on fruit: in vivo role and fumigation tools. Acta Horticulturae 518: 87-92.

Atkinson JD 1971. Diseases of tree fruits in New Zealand. Government Printer, Wellington, New Zealand. 406 p.

Beever RE, Laracy EP, Pak HA 1989. Strains of Botrytis cinerea resistant to dicarboximide and benzimidazole fungicides in New Zealand vineyards. Plant Pathology 38: 427-437.

Bowen JK, Rees-George J, Hill GN, Hahn M, Kemen E, Kucheryava N, Templeton MD, Plummer KM 2005. Investigation of fungal morphological differentiation in apple scab infection. Fungal Genetics Newsletter 52 (supplement): 111 (poster no. 247).

Brook PJ 1990. Review: Botrytis cinerea and fruit rot of kiwifruit, Actinidia deliciosa. DSIR Report to the Scientific Research Committee, New Zealand Kiwifruit Marketing Board. DSIR Plant Protection, Auckland, New Zealand. 99 p.

Bus V, Ranatunga C, Gardiner S, Bassett H, Rikkerink E 2000. Marker assisted selection for pest and disease resistance in the New Zealand apple breeding programme. Acta Horticulturae 538: 541-547.

Bus V, White A, Gardiner S, Weskett R, Ranatunga C, Samy A, Cook M, Rikkerink E 2002. An update on apple scab resistance breeding in New Zealand. Acta Horticulturae 595: 43-47.

Byrde RJW, Jordan, VWL 1977. Results in practice - IV. Fruit crops. In: Marsh RW ed. Systemic fungicides (Second edition). Longman, London. Pp. 274-293.

Castro M, Kramer K, Valdivia L, Ortiz S, Castillo A 2003. A double-stranded RNA mycovirus confers hypovirulence-associated traits to Botrytis cinerea. FEMS Microbiology Letters 228: 87-91.

Chester KS 1933. The problem of acquired physiological immunity in plants. The Quarterly Reviews of Biology 8: 275-324.

Chynoweth RW, Plummer KM 2004. Novel targets for sustainable control of apple blackspot. New Zealand Plant Protection 57: 349.

Cunningham GH 1925. Fungous diseases of fruit-trees in New Zealand and their remedial treatment. Brett, Auckland. 382 p.

Dawe AL, Nuss DL 2001. Hypoviruses and chestnut blight: exploiting viruses to understand and modulate fungal pathogenesis. Annual Review of Genetics 35: $1-29$.

Ebbole DJ, Jin Y, Thon M, Pan H, Bhattarai E, Thomas T, Dean R 2004. Gene discovery and gene expression in the rice blast fungus, Magnaporthe grisea: analysis of expressed sequence tags. Molecular Plant-Microbe Interactions 17: 1337-1347.

Elad Y, Stewart A 2004. Microbial control of Botrytis spp. In: Elad Y, Williamson B, Tudzynski P, Delen N ed. Botrytis: biology, pathology and control. Kluwer, Dordrecht. Pp. 223-241.

Elmer PAG, Hoyte SM, Vanneste JL, Reglinski T, Wood PN, Parry FJ 2005. Biological control of fruit pathogens. New Zealand Plant Protection 58: 47-54.

Fravel D, Olivain C, Alabouvette C. 2003. Fusarium oxysporum and its biocontrol. New Phytologist 157: 493-502.

Fullerton RA, Tyson JL 2002. Review of Phomopsis, Botryosphaeria and Cryptosporiopsis ripe rot pathogens of Hort16A. Part A. Biology and control. HortResearch Client Report 2003/132 to Zespri Innovation Ltd. HortResearch, Palmerston North, New Zealand. $55 \mathrm{p}$. 
Hartill WFT 1986. Resistance of plant pathogens to fungicides in New Zealand. New Zealand Journal of Experimental Agriculture 14: 239-245.

Heath MC 1995. Thoughts on the role and evolution of induced resistance in natural ecosystems, and its relationship to other types of plant defenses against disease. In: Hammerschmidt R, Kuc J ed. Induced resistance to disease in plants. Kluwer, Dordrecht. Pp. 141-151.

Hill MG, Fullerton R, Casonato S, Cheng CH, Manning M, Mauchline N, McKenna C, Reglinski T, Wurms KV 2004. Developing and implementing tools for measuring the resistance of Actinidia germplasm to pests and diseases - a review. HortResearch Client Report 14047 to Zespri Ltd. HortResearch, Palmerston North, New Zealand.101 p.

Howitt RLJ, Beever RE, Pearson MN, Forster RLS 1995. Presence of double-stranded RNA and virus-like particles in Botrytis cinerea. Mycological Research 99: 1472-1478.

Howitt RLJ, Beever RE, Pearson MN, Forster RLS 2001. Genome characterization of a Botrytis virus F, a flexuous rod-shaped mycovirus resembling plant "potex-like" viruses. Journal of General Virology 82: 67-78.

Kulakiotu EK, Thanassoulopoulos CC, Sfakiotakis EM 2004. Postharvest biological control of Botrytis cinerea on kiwifruit by volatiles of 'Isabella' grapes. Phytopathology 94: 1280-1285.

Leach JE, Cruz CMV, Bai JF, Leung H 2001. Pathogen fitness penalty as a predictor of durability of disease resistance genes. Annual Review of Phytopathology 39: 187-224.

Michailides TJ, Elmer PAG 2000. Botrytis gray mold of kiwifruit caused by Botrytis cinerea in the United States and New Zealand. Plant Disease 84: 208-223.

Ponciano G, Ishihara H, Tsuyumu S, Leach JE 2003. Bacterial effectors in plant disease and defense: keys to durable resistance. Plant Disease 87: 1272-1282.

Randall TA et al. [30 other authors] 2005. Large-scale gene discovery in the oomycete Phytophthora infestans reveals likely components of pathogenicity shared with true fungi. Molecular Plant-Microbe Interactions 18: 229-243.

Smedegaard-Petersen V, Tolstrup K 1985. The limiting effect of disease resistance on yield. Annual Review of Phytopathology 23: 475-490.

Tsai P-F, Pearson MN, Beever RE 2004. Mycoviruses in Monilinia fructicola. Mycological Research 108: 907-912.

Weeds PL, Beever RE, Long PG 2000. Competition between aggressive and nonaggressive strains of Botrytis cinerea (Botryotinia fuckeliana) on French bean leaves. Australasian Plant Pathology 29: 200-204.

Wurms KV 2005. Susceptibility to Botrytis cinerea, and curing-induced responses of lytic enzymes and phenolics in fruit of two kiwifruit (Actinidia) cultivars. New Zealand Journal of Crop and Horticultural Science 33: 25-34.

Wurms KV, Sharrock KR, Long PG, Greenwood DR, Ganesh S 1997. Responses of chitinases in kiwifruit to curing and to long-term storage. New Zealand Journal of Crop and Horticultural Science 25: 213-220.

Wurms KV, Long PG, Sharrock KR, Greenwood DR 1999. Review: The potential for resistance to Botrytis cinerea by kiwifruit. Crop Protection 18: 427-435.

Wurms KV, George MP, Lauren DR 2003. Involvement of phenolic compounds in host resistance against Botrytis cinerea in leaves of the two commercially important kiwifruit (Actinidia species) cultivars. New Zealand Journal of Crop and Horticultural Science 31: 221-233.

Yakoby N, Beno-Moualem D, Kobiler I, Prusky D 2002. The analysis of fruit protection mechanisms provided by reduced-pathogenicity mutants of Colletotrichum gloeosporioides obtained by restriction enzyme mediated integration. Phytopathology 92: 1196-1201. 